\title{
Correction to: Preoperative urine nitrite versus urine culture for predicting postoperative fever following flexible ureteroscopic lithotripsy: a propensity score matching analysis
}

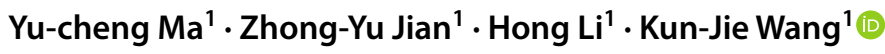

Published online: 15 September 2020

(c) Springer-Verlag GmbH Germany, part of Springer Nature 2020

\section{Correction to: World Journal of Urology \\ https://doi.org/10.1007/s00345-020-03240-w}

Table 3 shows the comparisons of baseline characteristics after applying PSM followed by IPTW two procedures. But, some columns of Table 3 were mislabeled in the original publication of the article. The corrected Table 3 now reports the comparisons of baseline characteristics after conducting PSM as well as those after further performing IPTW.

The original article can be found online at https://doi.org/10.1007/ s00345-020-03240-w.

* Kun-Jie Wang wangkj@scu.edu.cn

1 Department of Urology, Institute of Urology (Laboratory of Reconstructive Urology), West China Hospital, Sichuan University, Chengdu 610041, Sichuan, People's Republic of China 
Table 3 Comparison of baseline characteristics between 2 groups after PS-matching and IPTW analysis

\begin{tabular}{|c|c|c|c|c|c|c|c|c|}
\hline \multirow[t]{2}{*}{ Variables } & \multicolumn{4}{|l|}{ 1:4 PSM analysis } & \multicolumn{4}{|l|}{ IPTW analysis } \\
\hline & None-POF group & POF group & $P$ & $\begin{array}{l}\text { Standardized } \\
\text { difference }\end{array}$ & None-POF group & POF group & $P$ & $\begin{array}{l}\text { Standardized } \\
\text { difference }\end{array}$ \\
\hline Total fURS cases, $n(\%)$ & 96 & 24 & l & / & 31.44 & 31 & l & I \\
\hline $\begin{array}{l}\text { Gender } \\
\text { Female, } n(\%)\end{array}$ & $52(54.2)$ & $11(45.8)$ & 0.615 & 0.167 & $15.9(50.6)$ & $15(48.4)$ & 0.822 & 0.044 \\
\hline Age (year), mean (SD) & $53.45(12.59)$ & $50.33(13.82)$ & 0.290 & 0.236 & $50.60(12.35)$ & $50.55(12.74)$ & 0.984 & 0.004 \\
\hline BMI, mean (SD) & $24.16(2.88)$ & $23.76(2.89)$ & 0.540 & 0.140 & $24.24(3.03)$ & $24.18(2.79)$ & 0.907 & 0.022 \\
\hline Diabetes (YES), $n(\%)$ & $9(9.4)$ & $2(8.3)$ & 1.000 & 0.037 & $2.0(6.3)$ & $2(6.5)$ & 0.969 & 0.007 \\
\hline $\begin{array}{l}\text { Charlson comorbidity index, } \\
n(\%)\end{array}$ & & & 0.716 & 0.183 & & & 0.998 & 0.012 \\
\hline 0 & $77(80.2)$ & $20(83.3)$ & & & $25.4(80.9)$ & $25(80.6)$ & & \\
\hline 1 & $17(17.7)$ & $3(12.5)$ & & & $5.1(16.1)$ & $5(16.1)$ & & \\
\hline 2 & $2(2.1)$ & $1(4.2)$ & & & $0.9(3.0)$ & $1(3.2)$ & & \\
\hline $\begin{array}{l}\text { PCNL within } 12 \text { month, } \\
n(\%)\end{array}$ & $3(3.1)$ & $1(4.2)$ & 1.000 & 0.056 & $1.8(5.7)$ & $2(6.5)$ & 0.868 & 0.032 \\
\hline SWL within 12 month, $n(\%)$ & $6(6.2)$ & $2(8.3)$ & 1.000 & 0.080 & $2.1(6.7)$ & $2(6.5)$ & 0.958 & 0.011 \\
\hline URS within 12 month, $n(\%)$ & $5(5.2)$ & $2(8.3)$ & 0.922 & 0.125 & $2.1(6.6)$ & $2(6.5)$ & 0.971 & 0.007 \\
\hline $\begin{array}{l}\text { Stone burden }\left(\mathrm{cm}^{3}\right) \text {, median } \\
\text { (IQR) }\end{array}$ & $1.73(0.73,2.90)$ & $1.88(0.98,3.05)$ & 0.891 & 0.033 & $1.86(0.88,3.19)$ & $1.89(1.08,3.12)$ & 0.820 & 0.040 \\
\hline Stone location, $n(\%)$ & & & 0.412 & 0.506 & & & 1.000 & 0.056 \\
\hline Upper calyx & $6(6.2)$ & $1(4.2)$ & & & $1.0(3.3)$ & $1(3.2)$ & & \\
\hline Middle calyx & $8(8.3)$ & $2(8.3)$ & & & $2.0(6.2)$ & $2(6.5)$ & & \\
\hline Lower calyx & $12(12.5)$ & $3(12.5)$ & & & $3.3(10.4)$ & $3(9.7)$ & & \\
\hline Renal pelvis & $20(20.8)$ & $2(8.3)$ & & & $4.6(14.7)$ & $5(16.1)$ & & \\
\hline Ureteropelvic Joint & $1(1.0)$ & $2(8.3)$ & & & $2.3(7.2)$ & $2(6.5)$ & & \\
\hline Ureter & $6(6.2)$ & $2(8.3)$ & & & $2.2(6.9)$ & $2(6.5)$ & & \\
\hline Multiple locations & $43(44.8)$ & $12(50.0)$ & & & $16.1(51.3)$ & $16(51.6)$ & & \\
\hline Hydronephrosis (YES), $n(\%)$ & $64(66.7)$ & $15(62.5)$ & 0.885 & 0.087 & $18.1(57.5)$ & $18(58.1)$ & 0.952 & 0.012 \\
\hline $\begin{array}{l}\text { Urethal stent indewelling } \\
\text { (days), median (IQR) }\end{array}$ & $20(14,30)$ & $14(14,30)$ & 0.964 & 0.009 & $20(14,30)$ & $20(14,30)$ & 0.982 & 0.005 \\
\hline $\begin{array}{l}\text { Access sheath size }(14 / 16 \\
\text { Fr }), n(\%)\end{array}$ & $53(55.2)$ & $12(50)$ & 0.819 & 0.104 & $16.6(52.7)$ & $16(51.6)$ & 0.913 & 0.021 \\
\hline $\begin{array}{l}\text { Time in fURS (mins), mean } \\
\text { (SD) }\end{array}$ & $33.86(19.13)$ & $33.21(12.87)$ & 0.934 & 0.021 & $34.57(23.38)$ & $34.61(15.90)$ & 0.991 & 0.002 \\
\hline $\begin{array}{l}\text { Blood creatinine }(\mu \mathrm{mol} / \mathrm{L}) \text {, } \\
\text { mean }(\mathrm{SD})\end{array}$ & $93.62(37.10)$ & $85.86(22.85)$ & 0.330 & 0.252 & $95.27(42.59)$ & $94.46(33.33)$ & 0.908 & 0.021 \\
\hline $\begin{array}{l}\text { Urine bacterial }(n / \mu \mathrm{L}) \\
\text { median }(\mathrm{IQR})\end{array}$ & $41(16,126)$ & $136(57,483)$ & 0.438 & 0.184 & $73(23,385)$ & $150(69,452)$ & 0.846 & 0.036 \\
\hline $\begin{array}{l}\text { Urine leukocyte }(n / \mu \mathrm{L}) \\
\text { median }(\mathrm{IQR})\end{array}$ & $21(8,53)$ & $58(33,153)$ & 0.148 & 0.273 & $34(11,143)$ & $20(8,44)$ & 0.714 & 0.090 \\
\hline Urine pyocyte, $n(\%)$ & & & 0.260 & 0.467 & & & 0.987 & 0.033 \\
\hline Negative & $85(88.5)$ & $23(95.8)$ & & & $26.7(85)$ & $26(83.9)$ & & \\
\hline+ & $9(9.4)$ & $0(0.0)$ & & & $3.8(12.1)$ & $4(12.9)$ & & \\
\hline++ & $2(2.1)$ & $1(4.2)$ & & & $0.9(2.9)$ & $1(3.2)$ & & \\
\hline+++ & $0(0.0)$ & $0(0.0)$ & & & $0(0.0)$ & $0(0.0)$ & & \\
\hline $\begin{array}{l}\text { Albumin/Globulin ratio, } \\
\text { mean (SD) }\end{array}$ & $1.50(0.27)$ & $1.49(0.23)$ & 0.933 & 0.020 & $1.44(0.25)$ & $1.43(0.27)$ & 0.964 & 0.009 \\
\hline $\begin{array}{l}\text { Blood leukocyte }\left(10^{9} / \mathrm{L}\right), \\
\text { mean }(\mathrm{SD})\end{array}$ & $6.15(1.58)$ & $6.32(1.44)$ & 0.620 & 0.116 & $6.36(1.78)$ & $6.27(1.80)$ & 0.781 & 0.055 \\
\hline $\begin{array}{l}\text { International normalized } \\
\text { Ratio, mean (SD) }\end{array}$ & $0.96(0.08)$ & $0.98(0.08)$ & 0.257 & 0.259 & $0.97(0.07)$ & $0.97(0.07)$ & 0.920 & 0.019 \\
\hline Platelet $\left(10^{9} / \mathrm{L}\right)$, mean $(\mathrm{SD})$ & $174.08(69.52)$ & $198.62(79.08)$ & 0.135 & 0.330 & $199.35(78.38)$ & $191.9(72.83)$ & 0.613 & 0.098 \\
\hline
\end{tabular}

$S W L$ shock wave lithotripsy, $P C N L$ percutaneous nephrolithotomy, URS ureteroscopy, $f U R S$ flexible URS, BMI body mass index, $P O F$ postoperative fever, IQR interquartile range, $S D$ standard deviation. Standardized difference = IMean $1-$ Mean0|/sqrt $($ SD1 + SD0)/2) for continuous variables; Standardized difference = I(P1-P0|/ sqrt $((\mathrm{P} 1 *(1-\mathrm{P} 1)+\mathrm{P} 0 *(1-\mathrm{P} 0)) / 2)$ for categorical variables. it is generally agreed that a standardized difference of less than 0.1 indicates a negligible difference 